\title{
Network Formation of Catanionic Vesicles and Oppositely Charged Polyelectrolytes. Effect of Polymer Charge Density and Hydrophobic Modification
}

\author{
Filipe E. Antunes, ${ }^{\dagger, \ddagger}$ Eduardo F. Marques, ${ }^{\S}$ Ricardo Gomes, ${ }^{\dagger}$ Krister Thuresson, ${ }^{\ddagger}, \|$ \\ Björn Lindman, ${ }^{\dagger \neq}$ and Maria G. Miguel*,† \\ Chemistry Department, University of Coimbra, 3004-535 Coimbra, Portugal, \\ Physical Chemistry 1, Center for Chemistry and Chemical Enginering, Lund University, \\ P.O. Box 124, SE-221 00 Lund, Sweden, Centro de I nvestigação em Química, \\ Chemistry Department, University of Porto, 4169-007 Porto, Portugal, and Camurus AB, \\ I deon Science Park, SE-223 70 Lund, Sweden
}

Received J anuary 23, 2004. In Final Form: March 15, 2004

\begin{abstract}
In nonequimolar solutions of a cationic and an anionic surfactant, vesicles bearing a net charge can be spontaneously formed and apparently exist as thermodynamically stable aggregates. These vesicles can associate strongly with polymers in solution by means of hydrophobic and/or electrostatic interactions. In the current work, we have investigated the rheological and microstructural properties of mixtures of cationic polyelectrolytes and net anionic sodium dodecyl sulfate/didodecyldimethylammonium bromide vesicles. The polyel ectrolytes consist of two cationic cellulose derivatives with different charge densities; the lowest charge density polymer contains also hydrophobic grafts, with the number of charges equal to the number of grafts. F or both systems, polymer-vesicle association leads to a major increase in viscosity and to gel-like behavior, but theviscosity effects are more pronounced for theless charged, hydrophobically modified polymer. Evaluation of the frequency dependence of the storage and loss moduli for the two systems shows further differences in behavior: while the more long-lived cross-links occur for the more highly charged hydrophilic polymer, the number of cross-links is higher for the hydrophobically modified polymer. Microstructurestudies by cryogeni ctransmission el ectron mi croscopy indicatethat thetwo pol ymers affect the vesicle stability in different ways. With the hydrophobically modified polymer, the aggregates remain largely in the form of globular vesicles and faceted vesicles (polygon-shaped vesicles with largely planar regions). For the hydrophilic polycation, on the other hand, the surfactant aggregate structure is more extensively modified: first, the vesicles change from a gl obular to a faceted shape; second, there is opening of the bilayers leading to holey vesicles and ultimately to considerable vesicle disruption leading to planar bilayer, disklike aggregates. The faceted shape is tentatively attributed to a crystallization of the surfactant film in the vesicles. It is inferred that a hydrophobically modified polyion with relatively Iow charge density can better stabilize vesicles due to formation of molecularly mixed aggregates, while a hydrophilic polyion with relatively high charge density associates so strongly to the surfactant films, due to strong electrostatic interactions, that the vesicles are more perturbed and even disrupted.
\end{abstract}

\section{Introduction}

Rheological control and, in particular, gel-like appearance are important in many applications and have stimulated physicochemical investigations of systems with such properties. ${ }^{1-5}$ In particular, mixtures of surfactants and polymers are frequently employed for this purpose 6 and, sincea variety of combinations can be used, examples of possibleapplications arediverseand can beexemplified

* Author for correspondence. E-mail: mgmiguel@ci.uc.pt.

+ University of Coimbra.

‡ Lund University.

$\S$ University of Porto.

"Camurus AB.

(1) Bagger-J örgensen, H.; Coppola, L.; Thuresson, K.; Olsson, U.; Mortensen, K. Langmuir 1997, 13, 4204.

(2) Antunes, F.E.;Thuresson, K.; Lindman, B.; Miguel, M.G. Colloids Surf., A 2003, 215, 87.

(3) Filali, M.; Aznar, R.; Svenson, M.; Porte, G.; Appell, J . J . Phys. Chem. B 2001, 105, 10528.

(4) Karlson, L. Hydrophobically Modified Polymers-Rheology and Molecular Associations. Doctoral Dissertation, Physical Chemistry 1, University of Lund, 2002.

(5) Glass, J. E. Polymers in aqueous media: Performance through Association; Advances in Chemistry Series 223; American Chemical Society: Washington, DC, 1989.

(6) J önsson, B.; Lindman, B.; Holmberg, K.; Kronberg, B. Surfactants and Polymers in Aqueous Solution; J ohn Wiley \& Sons: New York, 1999. by detergents, shampoos, paints, and cosmetics. ${ }^{2,4,7-9}$ If a surfactant is added to a polymer solution, dramatic changes in viscosity are found if the polymer is of the associating type, in particular if it is a hydrophobically modified water-soluble polymer (HMP). However, the viscosity varies in a nonmonotonic way with thesurfactant concentration. There is at low surfactant concentrations a major increase in viscosity. Whiletheintroduction of ca. $1 \%$ of hydrophobic grafts on a water-soluble polymer typically leads to an order of magnitude increase in viscosity for a 1 wt \% solution in the absence of surfactant, the difference can amount to several orders of magnitude in the presence of low amounts of surfactant. However, viscosity only increases up to a certain surfactant concentration; thereafter it starts to decrease strongly and at high surfactant it reaches values much below the surfactant-freesituation. This behavior is well understood in terms of mixed aggregate formation between the surfactant and the HMP and of the significance of stoichiometry, i.e., the ratio between the number of

(7) Meier, W.; Hotz, J .; Günther-Ausborn, S. Langmuir 1996, 12, 5028

(8) Ranade\& Hollinger, Drug Delivery Systems; CRC Press Inc.: Boca Raton, FL, 1996.

(9) Lasic, D. D. Liposomes: from Physics to Applications; Elsevier: Amsterdam, 1993. 
surfactant micelles and the number of hydrophobic groups on the polymer molecules. ${ }^{10}$ Particularly strong association, and thus rheological effects, are found for the case of oppositely charged polymer-surfactant pairs. In this case there may, however, also be an associative phase separation over a certain concentration range. ${ }^{11}$

A large number of investigations has been performed on therheol ogical and microstructural properties of mixed solutions of HM Ps and surfactants, covering combinations of different types of cationic, anionic, and nonionic polymers and surfactants. ${ }^{2,12-17}$ With few exceptionsthese studies have been concerned with conditions where the surfactant self-assembles into small globular micelles. However, it can be expected that larger viscosities and/or more suitable rheological characteristics can be obtained with larger surfactant aggregates, likethreadlikemicelles, disklike aggregates, or vesicles. This was inter alia confirmed in an investigation where micellar growth was induced by various means. ${ }^{18} \mathrm{I}$ the present investigation we consider the case where the surfactant forms vesicles, with mixtures of charged vesicles and oppositely charged polymers in focus. I nteractions between polyelectrolytes and vesicles can, depending on the polymer, arise from different mechanisms: hydrophobic, 2,7,19-22 if a hydrophobic group is present in the polymer chain, electrostatic, ${ }^{21,23-25}$ or both hydrophobic and electrostatic. ${ }^{26-28}$ The polymers used in this study are both cationic cellulose derivatives, one, $\mathrm{HMP}^{+}(\mathrm{LM} 200)$, with hydrophobic grafts and of lower linear charge density and one, $\mathrm{P}^{+}$(J R400), of higher charge density without hydrophobicgroups. The surfactant mixture consists of the anionic surfactant sodium dodecyl sulfate (SDS) and the cationic surfactant didodecyl dimethylammonium bromide (DDAB).

It has been demonstrated that at certain mixing ratios of thetwo surfactants a negatively charged lamel lar phase appears and that at higher water contents, at rather low surfactant volumefractions, stablenegatively or positively charged catanionic vesicles form. ${ }^{29-31}$ It has also been

(10) Piculell, L.; Nilsson, S.; Sjostrom, J .; Thuresson, K. Associative Polymers in Aqueous Media; ACS Symposium Series 765; American Chemisal Society: Washington, DC, 2000; Chapter 19, pp 317-335.

(11) Lindman, B.; Thalberg, K. In Interactions of Surfactants with

Polymers and Proteins; CRC Press, Inc: Boca Raton, FL, 1993; p 252.

(12) Guillemet, F.; Piculell, L.; J . Phys. Chem. 1995, 99, 9203.

(13) Dualeh, A. J .; Steiner, C. A. Macromolecules 1990, 23, 251.

(14) Tanaka, R.; Meadows, j .; Williams, P. A.; Phillips, G. O.

Macromolecules 1992, 25, 1304

(15) Biggs, S.; Selb, J .; Candau, F. Langmuir 1992, 8, 838

(16) Magny, B.; Iliopoul os, I.; Zana, R.; Audebert, R. Langmuir 1994, 10, 3180.

(17) Annable, T.; Buscall, R.; Ettelaie, R.; Shepherd, P.; Whittlestone, D. Langmuir 1994, 10, 1060

(18) Nilsson, S.; Thuresson, K.; Hansson, P.; Lindman, B. J . Phys. Chem. B 1998, 102, 7099.

(19) Van de Pas, J . C.; Olsthoorn, T. M.; Schepers, F. J .; De Vries, C. H. E.; Buytenehek, C. J . Colloids Surf., A 1994, 85, 221.

(20) Loyen, K.; Iliopoul os, I .; Audebert, R.; Olsson, U. Langmuir 1995 11, 1053.

(21) Kevelam, J .; Breemen, J . F. L. v.; Blokzijl, W.; Engberts, J . B. F. N. Langmuir 1996, 12, 4709.

(22) Polozova, A. Biochim. Biophys. Acta 1997, 1326, 213.

(23) Raudino, A.; Castelli, F. Macromol ecules 1997, 30, 2495

(24) Everaars, M. D.; Nieuwkerk, A. C.; Denis, S.; Marcelis, A. T. M.; Sudhölter, E. J. R. Langmuir 1996, 12, 4043.

(25) Porcar, I.; Garcia, R.; Gómez, C.; Campos, A.; Abad, C. Polymer 1997, 38, 5107.

(26) Ashbaugh, H.; Boon, K.; Prud'homme, R. Colloid Polym. Sci. 2002, 280, 783 .

(27) Yaroslavov, A. A.; Koulkov, V. Y.; Yaroslavova, E. G.; I gnatiet, M. O.; Kabanov, V. A. Langmuir 1998, 14, 5999.

(28) Marques, E. F.; Regev, O.; Khan, A.; Miguel, M. G.; Lindman

B. Macromolecules 1999, 32, 6626.

(29) Kaler, E. W.; Murthy, A. K.; Rodriguez, V. E.; Zasadzinsky, J A. N. Science 1989, 245, 1371.

(30) Kaler, E. W.; Herrington, K. L.; Murthy, A. K.; Zasadzinsky, J

A. N. J . Phys. Chem. 1992, 96, 6698.

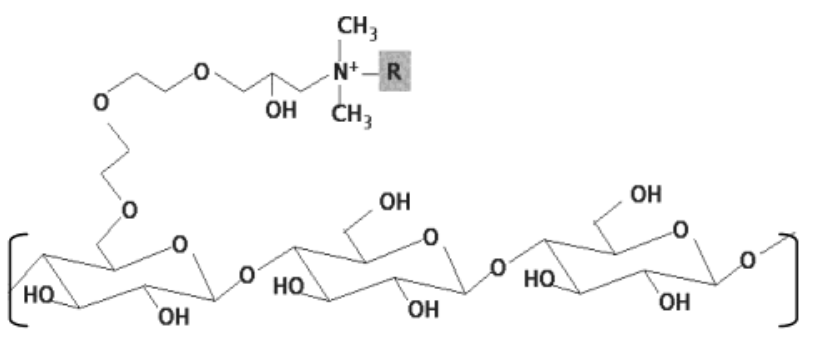

JR400: $\mathrm{R}=\mathrm{CH}_{3}$

LM200: $\mathrm{R}=\mathrm{C}_{12} \mathrm{H}_{25}$

Figure 1. Schematicrepresentation of thechemical structure of the two cationic cellulose derivatives that were used in the present investigation: J R400 $=\mathrm{P}^{+}$; LM200 $=\mathrm{HMP}^{+}$.

shown that when an aqueous solution of such vesicles is mixed with an oppositely charged polymer, threedifferent regions can be found ${ }^{28,32}$

(I) A phaseseparation regi on, where a precipitate forms in equilibrium with a bluish solution. Thephaseseparation is of the associative type, the precipitate being a coacervation complex of surfactant and polymer with a (near) zero net charge.

(II) A monophasic low viscous solution where there is enough excess of surfactant in solution to dissolve the precipitate.

(III) A ge region, at excess polymer, where the precipitate is redissolved.

In our work the polymer has a positive charge and at overall charge neutralization the fraction of positive charges is 0.5; wewill in this paper denotesuch conditions by $\mathrm{f}_{\mathrm{p}}{ }^{+}=0.50$, where $\mathrm{f}_{\mathrm{p}}{ }^{+}$is defined by eq 1 below. In this work the redissolution occurs at $\mathrm{f}_{\mathrm{p}}{ }^{+}=0.54$ for the system which contains the higher charged polymer $\left(\mathrm{P}^{+}\right)$, while for thesystem with thelower charged and hydrophobically modified polymer $\left(\mathrm{HMP}^{+}\right)$, redissolution appears at $\mathrm{f}_{\mathrm{p}}^{+}=$ $0.57 .{ }^{28}$ The region is referred to as the gel region, because samples are highly viscous.

Previously, the association in this system has been studied by establ ishing a phase map. ${ }^{28} \mathrm{~F}$ or a more precise microstructural basis, cryogenic transmission electron microscopy (cryo-TE M) investigations wereperformed and compared with novel rheological studies. It is found that the ${ }^{+}$system is characterized by relatively long relaxation times compared to the lower charged $\mathrm{HMP}^{+}$system. On theother hand, thelatter showed hi gher viscosity. Rather important changes in the surfactant aggregate shape are also reported and the mechanisms lying behind it discussed.

\section{Experimental Section}

Materials. Surfactants, sodium dodecyl sulfate (SDS) and didodecyldimethylammonium bromide (DDAB), were obtained from Aldrich and were used without further purification. The vesicles formed had an average molecular weight of $1.04 \times 10^{5}$ and an aggregation number, $\mathrm{N}_{\mathrm{Agg}}$, of approximately $15000.28,31$ Thetwo different cationic pol yel ectrolytes, $\mathrm{P}^{+}\left(\mathrm{R}\right.$ R 400) and $\mathrm{HMP}^{+}$ (LM 200), are hydroxyethyl cellulose derivatives that were manufactured by Union Carbide Chemicals and Plastics Company, I nc. A pproxi matestructural formulas areshown in Figure 1. The J R400 N,N,N-trimethylammonium derivative has approximately one positive charge every second nanometer along the polymer chain. I n a 1 wt \% aqueous solution this corresponds

(31) Marques, E. F.; Regev, O.; Khan, A.; Miguel, M. G.; Lindman B. J . Phys. Chem. B 1998, 102, 6746.

(32) Piculell, L.; Lindman, B.; Karlström, G. Phase Behavior of Polymer/ surfactant systems; Kwak, J. C. T., Ed.; Marcel Dekker: New York, 1998. 
to a concentration of charges of about $10 \mathrm{~mm} .{ }^{33}$ Since $\mathrm{P}^{+}$has a molecular weight of about $500 \mathrm{kD}$, each polymer chain has an approximate contour length of $1000 \mathrm{~nm} \cdot{ }^{34}$ LM 200 is a N,Ndimethyl-N-dodecylammonium derivative that on average has approximately one positive charge every $10 \mathrm{~nm}$, or about $2 \mathrm{~mm}$ of charge in a 1 wt \% aqueous solution. Since this polymer has a lower molecular weight (approximately 100 kD), the average contour length is much shorter (on average about $200 \mathrm{~nm}$ ). ${ }^{33-35}$ Both polymers render their charge from quaternary ammonium groups; however the ammonium group on $\mathrm{HMP}^{+}$also contains a dodecyl chain. The degree of hydrophobic modification of $\mathrm{HMP}^{+}$ is about 5.4 hydrophobic chains per 100 sugar residues.

An estimation of the surface density of the vesicles yields approximately 1 net negativecharge per $\mathrm{nm}^{2}$, as calculated from the equation

$$
\mathrm{d}_{-}=\frac{\left(\mathrm{x}_{\mathrm{SDS}}-\mathrm{x}_{\mathrm{DDAB}}\right) \mathrm{N}_{\mathrm{agg}}}{8 \pi \mathrm{R}_{\mathrm{ves}}{ }^{2}}
$$

where $\mathrm{d}_{-}$is the density of the negative charges in the vesicles, $X_{\text {SDS }}$ and $X_{D D A B}$ are the SDS and DDAB molar fractions in the surfactant mixture, respectively, $\mathrm{N}_{\text {agg }}$ is theaggregation number of the vesicles, and $R_{\text {ves }}$ is the vesicle average radius. ${ }^{28}$

The molar fraction of polymer charge in the mixture, $\mathrm{fp}_{\mathrm{p}}^{+}$, is defined as

$$
\mathrm{f}_{\mathrm{p}}^{+}=\frac{\mathrm{C}_{\mathrm{p}^{+}}}{\mathrm{C}_{\mathrm{p}^{+}}+\mathrm{C}_{\mathrm{S}^{-}}}
$$

where $\mathrm{C}_{\mathrm{p}^{+}}$is the polymer charge molal concentration and $\mathrm{C}_{5^{-}}$is the molal concentration of thenet surfactant charge $\left(\mathrm{C}_{\mathrm{S}^{-}}=\mathrm{C}_{\mathrm{SDS}}\right.$ $-C_{\text {DDAB }}$.

Methods. Samples were prepared in the following way. A 55 mm surfactant stock solution $\left(\mathrm{C}_{\text {surf }}=\mathrm{C}_{\mathrm{SDS}}+\mathrm{C}_{\mathrm{DDAB}}\right)$ with a mole fraction of SDS corresponding to $0.71\left(\mathrm{X}_{\mathrm{SDS}}=\mathrm{C}_{\mathrm{SDS}} /\left(\mathrm{C}_{\mathrm{SDS}}+\mathrm{C}_{\mathrm{DDAB}}\right)\right)$ was prepared by mixing a SDS micellar solution and a DDAB homogenized dispersion. This resulted in a bluish solution containing vesides bearing anionicnet charge. ${ }^{31}$ Vesiclesol utions were sonicated for $5 \mathrm{~min}$. Surfactant-polymer samples were prepared by mixing solid polymer and veside stock solution in appropriate amounts to obtain samples al ong lines defined by constant surfactant content (varying polymer content) or constant polymer content (varying surfactant content).

For an easier way to correl ate with the phase map, Figure 2, mixed samples are denoted in the figures and legends as J XSy or LxSy, where J and L represent $\mathrm{P}^{+}\left(\mathrm{R}\right.$ 400) and $\mathrm{HMP} \mathrm{P}^{+}(\mathrm{LM} 200)$, respectively, $x$ is the polymer weight content (wt \%), and $y$ is the surfactant concentration (mm).

M ost of thesesamples havea high viscosity and weretherefore prepared in the following way: The samples were mixed with the aid of a vortex mixer before heating to a temperature of about $50^{\circ} \mathrm{C}$ for approximately $30 \mathrm{~min}$. After heating, thesamples were again subject to vortex mixing. With increase of temperature, the viscosity of the samples decreases, which facilitates mixing. In samples containing $\mathrm{HMP}^{+}$(LM 200), it has actually been found that without heating, a mixture of cloudy domains and clear gel areas appears. ${ }^{28}$ Gentle temperature cycles do not invol veimportant input of energy other than to dispersecolloidal entities. After three to five repeated cycles (mixing-heatingmixing), depending of sample consistency, the samples were centrifuged at $25^{\circ} \mathrm{C}$ for approximately $6 \mathrm{~h}$ to removeair bubbles. All samples submitted to rheological tests were monophasic.

A Reol ogica Stress Tech rheometer equi pped with an automatic gap setting was used for the rheological measurements. The instrument can be run either in the controlled stress or in the controlled strain mode. A coneand plategeometry was employed, and to minimize evaporation, a solvent trap system was used. Prior to any oscillatory deformation test, the linear viscoelastic region for each sample was determined by stress sweep tests.

(33) Thuresson, K.; Nilsson, S.; Lindman, B. Langmuir 1996, 12, 530.

(34) Dhoot, S.; Goddard, E. D.; Harris, E. C.; Murphy, D. S. Colloids Surf. 1992, 66, 91

(35) Guillemet, F. Thèse de Doctorat, Université de Paris VI, 1995.
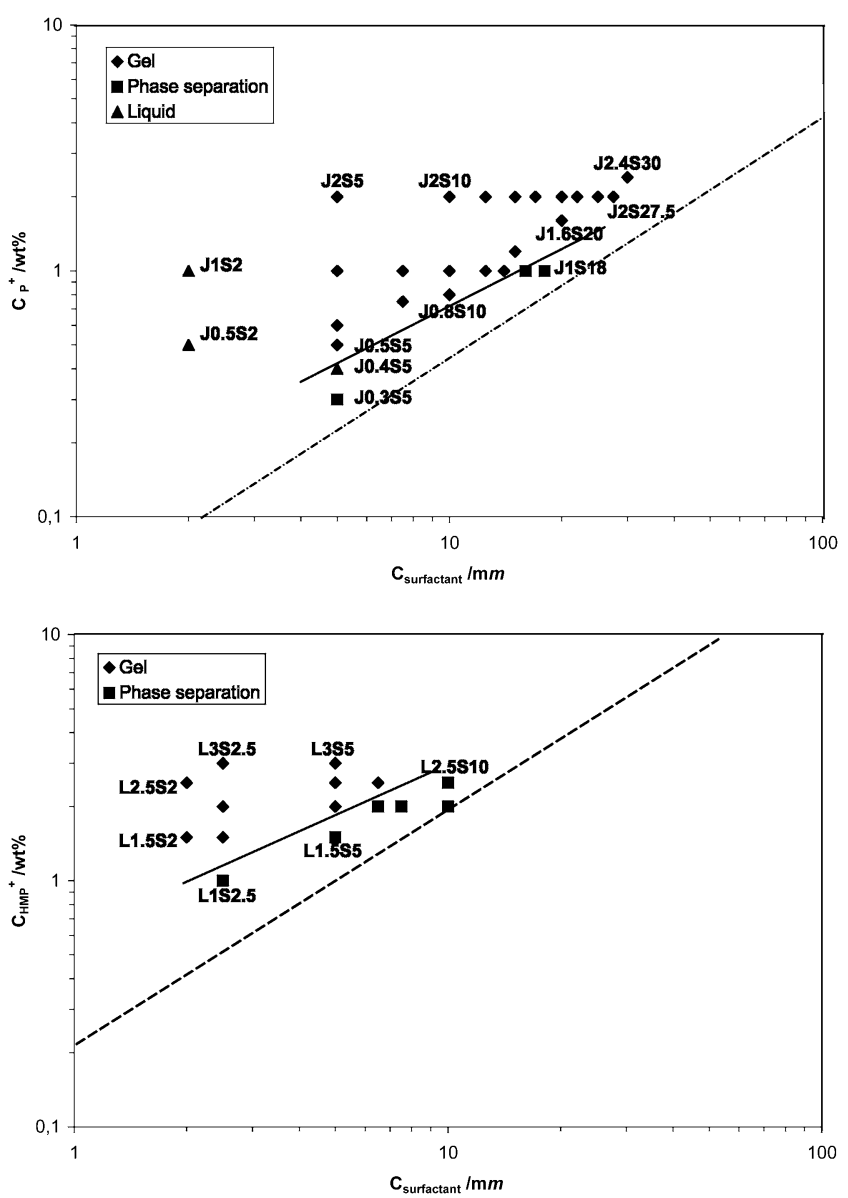

Figure 2. Characterization of sample composition for the $\mathrm{P}^{+}$ (J R400) system (top) and for the $\mathrm{HMP}^{+}$(LM200) system (bottom). I n the present study $X_{\mathrm{SDS}}=0.71$ has been used, where $\mathrm{X}_{\text {SDS }}$ corresponds to the molar fraction of SDS in a SDS/DDAB solution. Redissol ution of the complex appears when thefraction of polymer charge, $\mathrm{f}_{\mathrm{p}}{ }^{+}$, is 0.54 for the $\mathrm{P}^{+}$system, while for the $\mathrm{HMP}^{+}$system redissol ution appears at $\mathrm{f}_{\mathrm{p}}{ }^{+}=0.57$. The dotted line indicates charge neutralization and the solid line the precipitation boundary. Samples are denoted as J xSy or LxSy, where $\mathrm{J}$ and $\mathrm{L}$ represent $\mathrm{P}^{+}$and $\mathrm{HMP}^{+}$, respectively, $\mathrm{x}$ is the polymer weight content (wt \%), and $y$ is the surfactant concentration (millimolal).

M easurements within thelinear region ensurethat themeasured rheol ogical properties are independent of the applied stress and that (near) equilibrium properties are probed.

In addition to oscillatory shear measurements, dynamic viscosity and shear-thinning wereal sostudied by rotational shear tests. All experiments wererun at a constant temperature of 25 ${ }^{\circ} \mathrm{C}$.

A Philips CM 120 Bio-twin microscope was used for cryogenic transmission electron microscopy (cryo-TE M) studies. Samples were placed in a vitrification chamber in which temperatureand humidity can be controlled. In particular humidity can be held dosetosaturation to prevent sampleevaporation. ${ }^{36} \mathrm{~A}$ small drop (ca. $5 \mu \mathrm{L}$ ) was put on a copper grid supported carbon coated hol ey film. ${ }^{37}$ I mmediately after blotting with filter paper to obtain a thin liquid film over the grid, the sample is plunged into liquid ethane (at its melting temperature). The vitrified film is then transferred under liquid nitrogen to the electron microscope.

\section{Results}

Polycation-Vesicle Complexes and Phase Behavior. The pseudoternary surfactant system SDS/DDAB/

(36) Bellare, J . R.; Davis, H. T.; Scriven, L. E.; Talmon, Y.J . Electron Microsc. Technol. 1998, 10, 87.

(37) Vinson, P. K. The 45th Annual Meeting of the Electron Microscopy Society of America, San Francisco, CA, 1987. 
water is used as a basis for the present investigation. ${ }^{31,38}$ (Any system of two el ectrolytes without common ion must from a thermodynamic point of view be treated as a quaternary system. Thus separating phases do not have compositions falling in the triangular diagram representing theisothermal mixing of water and thetwo surfactants. Here we are concerned with the homogeneous solution phases, where this complication does not enter.) By themselves the two surfactants have critical packing parameters (CPPs) that suggest formation of aggregates curving toward oil $\left(C P P_{S D S}=0.33\right.$ and $\left.C_{D P} P_{D A B}=0.8\right)$. This is largely due to the ionic headgroups of these molecules. By mixture of anionicSDS with cationicDDAB, the effective headgroup area in the mixed aggregates decreases since opposite charges favor cl oser packing. At certain mixing ratios, lamellar structures form and a limited vesicular region can be found..$^{31}$ In the present study $X_{\text {SDS }}=0.71$ was chosen; here small unilamellar vesicles (SUVs) are the dominant aggregates while multilamellar vesicles (MLVs) are sparsely detected. At this mixing ratio, vesicles arenegatively charged and have a spherical shape with sizes in the range $20-70 \mathrm{~nm}$, with an average size of $30 \mathrm{~nm}$. The vesicular region is limited to the surfactant concentration range $C_{s}=5-50 \mathrm{~mm}$. At a higher concentration $\left(\mathrm{C}_{\mathrm{s}}>58 \mathrm{~mm}\right)$ a heterogeneous region with a bluish solution and a cl oudy phaseseparation of lamellar liquid crystal appears. For low concentrations $\left(\mathrm{C}_{\mathrm{s}}<5 \mathrm{~mm}\right)$, a catanionic solid (precipitate or flocs) is present in equilibrium with solution. ${ }^{31}$

In a previous study, the effect of adding two polycations to different surfactant compositions in this system has been reported. ${ }^{28}$ The same (pseudoquaternary) polymer surfactant systems were used here, and interestingly it was found in the present investigation that the presence of polyel ectrolyteprevents phase separation at surfactant concentrations lower than $5 \mathrm{~mm}$ (this has been checked down to $2 \mathrm{~mm}$ ). Composition maps with macroscopic appearance of samples indicated are shown in Figure 2. The line indicates $\mathrm{f}_{\mathrm{p}}{ }^{+}=0.50$.

Rheological Characterization. Samples within the gel region have been investigated with respect to the rheological behavior.

Figure 3 shows typical mechanical spectra for the two polymer systems, with storage, G', and loss, G", moduli, as functions of the oscillation frequency. Following other associating polymer systems, the storageand loss modul i increase with increasing frequency, i.e., with decreasing observation time. The $\mathrm{HMP}^{+}$system shows a commonly observed behavior of G" being larger at low frequencies and $\mathrm{G}^{\prime}$ at high frequencies, i.e., of a progressivechangeover from dominating viscous effects at low frequencies to dominating elastic properties at high frequencies. From this behavior, a formation of a three-dimensional network can be deduced and the lifetime of the cross-links can be estimated from the inverse of the angular frequency at which $\mathrm{G}^{\prime}$ and $\mathrm{G}^{\prime \prime}$ cross. For the $\mathrm{P}^{+}$samples, in general $\mathrm{G}^{\prime}$ exceeds $G^{\prime \prime}$ over the entire frequency range accessible; i.e., the cross-link lifetimes are very long. This behavior was found for almost all $\mathrm{P}^{+}$samples, except for low surfactant and polymer concentrations, where relaxation times could be easily measured. Typically thus the $\mathrm{P}^{+}$ system displays a gel-like behavior for all studied frequencies; $\mathrm{HMP}^{+}$samples are viscoel astic with a gel-like behavior at high enough frequencies and a liquidlike behavior for low frequencies. On the other hand, $\mathrm{HMP}^{+}$ samples show higher storage moduli than the system

(38) Marques, E.; Khan, A.; Miguel, M. G.; Lindman, B. J . Phys. Chem. 1993, 97, 4729 .

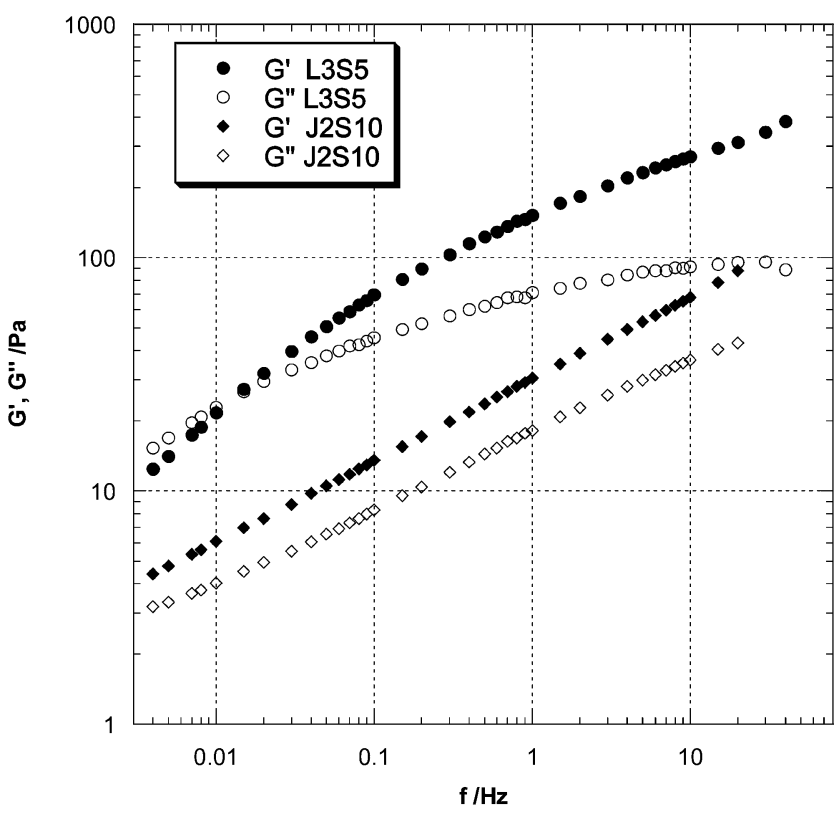

Figure 3. Typical mechanical spectra for $\mathrm{P}^{+}$and $\mathrm{HMP}^{+}$ systems. Figure shows results for 2 wt $\% \mathrm{P}^{+}$and $10 \mathrm{~mm}$ surfactant ( $2 \mathrm{S10}$ ) and $3 \mathrm{wt} \% \mathrm{HMP}^{+}$and $5 \mathrm{~mm}$ surfactant (L3S5).

composed of the polycation without hydrophobic modification. Analogous observations were found from the analysis for other conditions, i.e., 5, 7.5, 10, 12.5, 15, and $20 \mathrm{~mm}$ surfactant concentration (in the $\mathrm{P}^{+}$system) and $2,2.5,5$, and $6.5 \mathrm{~mm}$ surfactant concentration (in the $\mathrm{HMP}^{+}$system). Table 1 illustrates the variation of the relaxation times and storage moduli at high frequencies with composition. In the case of the $\mathrm{P}^{+}$system, some of therelaxation times (indicated in Table 1 as a lower limit) areeither bel ow theaccessiblefrequency or display a noisy regime. Both relaxation time and storage modulus general ly increase with polymer and surfactant concentration, as seen in Table 1. However, a maximum in the storage modulus and relaxation time is observed in the surfactant concentration sweep and will be discussed below.

Figure 4 shows the dependence of $\mathrm{G}^{\prime}$ on the polymer concentration (at a constant surfactant concentration of $5 \mathrm{~mm}$ ). An increase of the polyel ectrolyte concentration, and thus of thenumber of possiblebridges, is accompanied by an increase of the elastic and loss moduli. This was seen particularly at intermediate and high frequencies.

Concerning the $\mathrm{P}^{+}$system, samples are generally characterized by a larger $\mathrm{G}^{\prime}$ than $\mathrm{G}^{\prime \prime}$ in the investigated frequency range. Thus, relaxation times are long and all samples either are self-supporting (test tubes can betilted upside down without sampleflow) or flow very slowly, as is illustrated in Figure 5. For low amounts of polymer and surfactant, for instance 0.455 , el astic properties areonly displayed at high frequencies.

With $\mathrm{HMP}^{+}$, the situation is quite different. Despite $\mathrm{G}^{\prime}$ moduli having larger numerical values, the relaxation times are shorter, as seen by a crossover of $\mathrm{G}^{\prime}$ and $\mathrm{G}^{\prime \prime}$ within thestudied frequency interval. The $\mathrm{HMP}^{+}$polymer thus can be seen to give mixtures with higher viscosity as compared to the $\mathrm{P}^{+}$polymer that gives more elastic mixtures (longer lived cross-links). A rheological comparison of the two polymers in samples with the same composition (and far away from the phaseseparation line) was performed and underlines the described tendencies. The presence of equal weight percentage of polycation signifies that the number of positive charges is fi ve times larger in the $\mathrm{P}^{+}$sample and that there are five times as 
Table 1. Relaxation Times and Storage Moduli for $\mathbf{P}^{+} /$SDS/DDAB and HMP ${ }^{+} /$SDS/DDAB Systems for Different Polymer and Surfactant Concentrations

\begin{tabular}{cllc}
\hline surfactant & $\mathrm{P}^{+}$ & $\tau / \mathrm{s}$ & $\mathrm{G}^{\prime}(10 \mathrm{~Hz}) / \mathrm{Pa}$ \\
\hline 2 & 0.5 & 26.5 & 4.72 \\
& 1 & $>10.6$ & 4.70 \\
5 & 0.4 & $>1.45$ & 1.53 \\
& 0.5 & $>39.7$ & 10.3 \\
& 0.6 & $>26.5$ & 18.7 \\
& 1 & $>39.7$ & 25.2 \\
7.5 & 2 & $>39.7$ & 30.0 \\
& 0.75 & $>26.5$ & 27.8 \\
10 & 1 & $>79.5$ & 33.8 \\
& 0.8 & $>79.5$ & 20.7 \\
12.5 & 1 & $>159$ & 50.1 \\
& 2 & $>159$ & 67.5 \\
15 & 1 & $>79.5$ & 47.4 \\
& 2 & $>79.5$ & 101 \\
20 & 1.2 & $>79.5$ & 50.2 \\
& 2 & $>17.6$ & 71.8 \\
30 & 1.6 & $>39.7$ & 60.6 \\
& 2 & $>79.5$ & 151 \\
& 2.4 & $>19.9$ & 93.5
\end{tabular}

\begin{tabular}{cccc}
\hline surfactant & $\mathrm{HMP}^{+}$ & $\tau / \mathrm{s}$ & $\mathrm{G}^{\prime}(10 \mathrm{~Hz}) / \mathrm{Pa}$ \\
\hline 2 & 1.5 & 7.58 & 32.0 \\
& 2.5 & 0.640 & 78.0 \\
2.5 & 1.5 & 2.27 & 26.1 \\
& 2 & 3.98 & 84.0 \\
5 & 3 & 1.22 & 135 \\
& 2 & 22.7 & 43.1 \\
& 2.5 & 22.7 & 142 \\
& 3 & 14.4 & 271
\end{tabular}

\begin{tabular}{|c|c|c|c|}
\hline $\mathrm{P}^{+}$ & surfactant & $\tau / \mathrm{s}$ & $\mathrm{G}^{\prime}(10 \mathrm{~Hz}) / \mathrm{Pa}$ \\
\hline \multirow[t]{2}{*}{0.5} & 2 & 26.5 & 4.72 \\
\hline & 5 & > 39.7 & 10.3 \\
\hline \multirow[t]{6}{*}{1} & 2 & $>10.6$ & 4.70 \\
\hline & 5 & 39.7 & 25.2 \\
\hline & 7.5 & $>79.5$ & 33.8 \\
\hline & 10 & $>159$ & 50.1 \\
\hline & 12.5 & $>79.5$ & 47.4 \\
\hline & 14 & $>159$ & 25.7 \\
\hline \multirow[t]{8}{*}{2} & 5 & 39.7 & 30.0 \\
\hline & 10 & $>159$ & 67.5 \\
\hline & 12.5 & $>79.5$ & 101 \\
\hline & 15 & $>17.6$ & 71.8 \\
\hline & 20 & $>79.5$ & 151 \\
\hline & 22 & $>10.6$ & 169 \\
\hline & 25 & $>15.9$ & 148 \\
\hline & 27.5 & $>31.8$ & 90.8 \\
\hline $\mathrm{HMP}^{+}$ & surfactant & $\tau / \mathrm{s}$ & $\mathrm{G}^{\prime}(10 \mathrm{~Hz}) / \mathrm{Pa}$ \\
\hline \multirow[t]{2}{*}{1.5} & 2 & 7.58 & 32.0 \\
\hline & 2.5 & 2.27 & 26.1 \\
\hline \multirow[t]{2}{*}{2} & 2.5 & 3.98 & 84.0 \\
\hline & 5 & 22.7 & 43.1 \\
\hline \multirow[t]{3}{*}{2.5} & 2 & 0.640 & 78.0 \\
\hline & 5 & 22.7 & 142 \\
\hline & 6.5 & 15.9 & 92.4 \\
\hline \multirow[t]{2}{*}{3} & 2.5 & 1.22 & 135 \\
\hline & 5 & 14.4 & 271 \\
\hline
\end{tabular}

many $\mathrm{HMP}^{+}$chains as thereare ${ }^{+}$chains; thetotal length of $\mathrm{P}^{+}$chains is obviously similar to that of $\mathrm{HMP}^{+}$chains. Thestorage modul $i$ was al so compared for high frequencies (again $\mathrm{HMP}^{+}$has higher storage modulus than $\mathrm{P}^{+}$), which gives information about the number of active links (bridges). ${ }^{39} \mathrm{~N}$ otethat $\mathrm{G}_{\infty}$ (plateau of $\mathrm{G}^{\prime}$ at high frequencies) is proportional to the bridge density; some stiff gels (as in our case) cannot achieve the plateau and $\mathrm{G}^{\prime}$ at high frequencies is used as a factor to give qualitative information about the active chain density.

(39) Ferry, J . Viscoel astic Properties of polymers, 3rd ed.; J ohn Wiley \& Sons: New York, 1980.

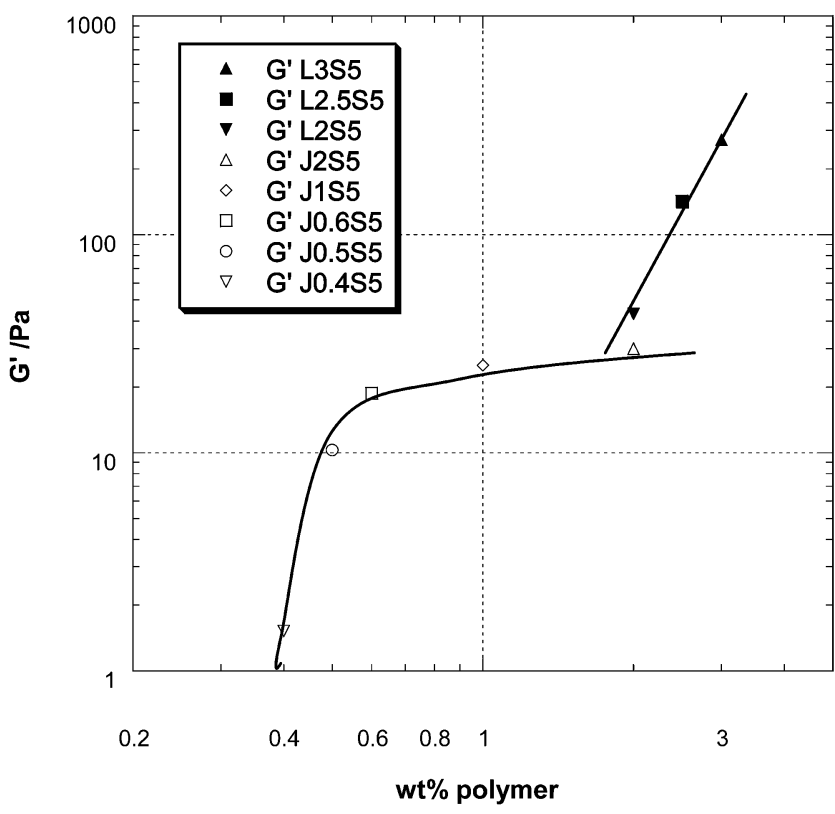

Figure 4. Storage modulus as a function of polymer concentration. $\mathrm{C}_{\mathrm{s}}=5 \mathrm{~mm}$ and frequency $=10 \mathrm{~Hz}$. Solid symbols stand for $\mathrm{HMP}^{+}$and open symbols indicate $\mathrm{P}^{+}$. Samples are denoted as] XSy or LxSy where J and $L$ represent $\mathrm{P}^{+}\left(\mathrm{J}\right.$ R 400) and $\mathrm{HMP}^{+}$ (LM 200), respectively, x represents the polymer weight content (wt \%), and y the surfactant concentration ( $\mathrm{mm})$. The lines are just meant to be guide for the eye.
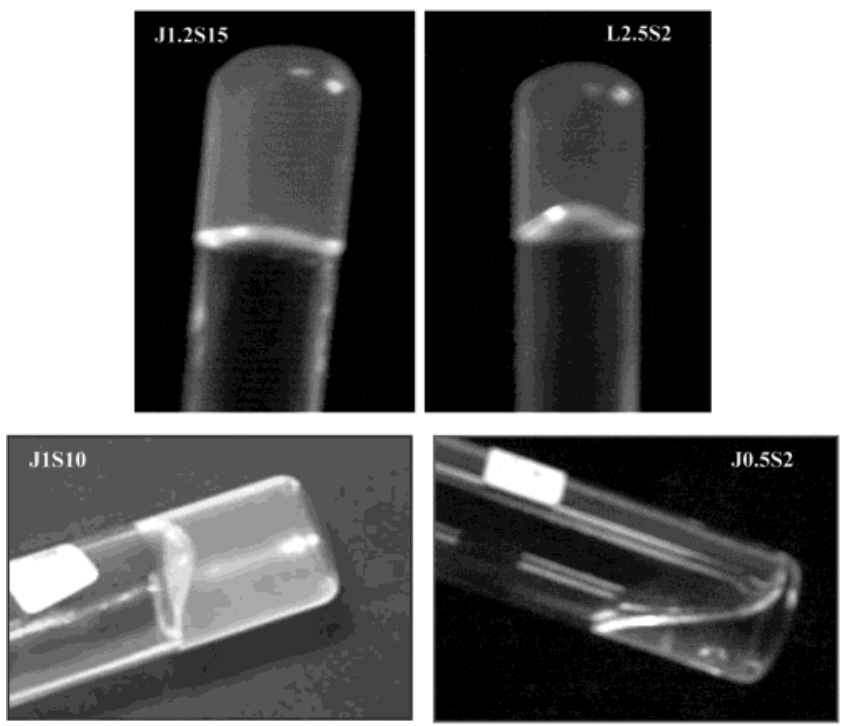

Figure 5. Samples composed of 1.2 wt $\% \mathrm{P}^{+}$and $15 \mathrm{mM}$ surfactant (J 1.2S15), $2.5 \mathrm{wt} \% \mathrm{HMP}^{+}$and $2 \mathrm{mM}$ surfactant (L 2.5S2), 1 wt \% $\mathrm{P}^{+}$and $10 \mathrm{mM}$ surfactant (J 1S10), and $0.5 \mathrm{wt}$ $\% \mathrm{P}^{+}$and $2 \mathrm{mM}$ surfactant (J 0.5S2). J 0.5S2 flows easily while the other samples show a gel-like behavior.

The complex viscosity, $\eta^{*}$, and thestorage modulus, $\mathrm{G}^{\prime}$, are larger in the $\mathrm{HMP}^{+}$system, which gives evidence for the importance of the hydrophobic modification. $\mathrm{P}^{+}$ samples are more elastic, as seen by a longer relaxation timewhich is even outsidethefrequency interval studied, and, thus, significantly longer than the relaxation time for $\mathrm{HMP}^{+}$.

Figure 6 shows the storage modulus as a function of $\mathrm{f}_{\mathrm{p}}{ }^{+}$ and vesicle volume fraction, $\phi_{v}$, calculated from an expression relating vesicle volume, surfactant concentration, $\mathrm{C}_{\text {surf, }}$ and aggregation number, $\mathrm{N}_{\text {agg }}$

$$
\phi_{\mathrm{v}}=4 \pi \mathrm{R}_{\mathrm{ves}}{ }^{3} \mathrm{C}_{\text {surf }} \mathrm{N}_{\mathrm{A}} / 3 \mathrm{~N}_{\text {agg }}
$$



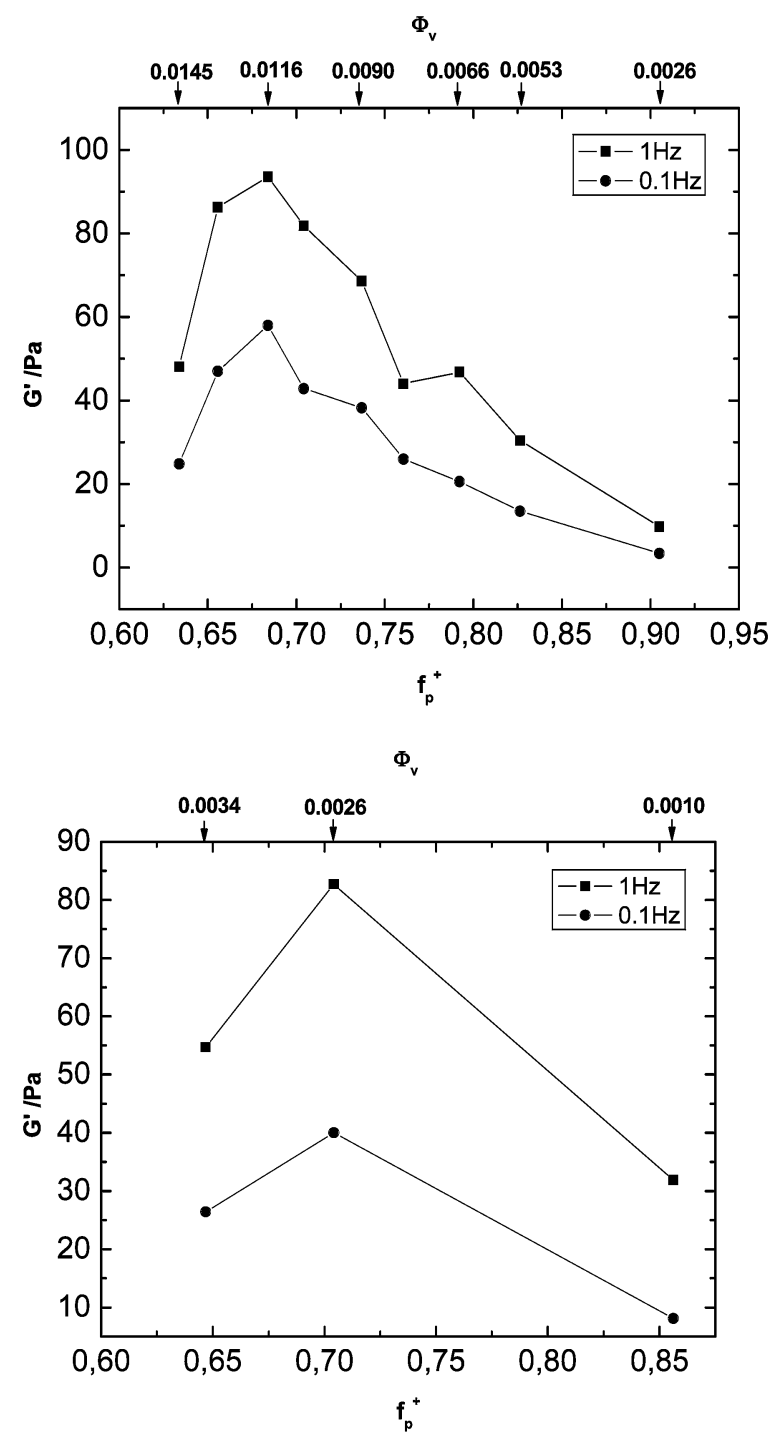

Figure 6. Storage modulus as a function of $\mathrm{f}_{\mathrm{p}}{ }^{+}$and vesicle volumefraction, $\phi_{\text {ves }}$, at two different frequencies. The pol ymer concentration is constant: 2 wt \% for $\mathrm{P}^{+}$(top) and $2.5 \mathrm{wt} \%$ for $\mathrm{HMP}^{+}$(bottom). The lines are just meant to be a guide for the eye.

where $\mathrm{N}_{\text {agg }}$ is defined as

$$
\mathrm{N}_{\mathrm{agg}}=8 \pi \mathrm{R}_{\mathrm{ves}}^{2} / \mathrm{a}_{\mathrm{s}}
$$

where $a_{s}$ is the average surfactant headgroup area, $R_{\text {ves }}$ is the vesicle radius, $\mathrm{N}_{\mathrm{A}}$ is Avogadro's number, and $\mathrm{C}_{\text {surf }}$ is the total surfactant concentration. Equations 3 and 4 can be related to obtain the expression ${ }^{26,31}$

$$
\phi_{\mathrm{v}}=\mathrm{a}_{\mathrm{s}} \mathrm{R}_{\text {ves }} \mathrm{N}_{\mathrm{A}} \mathrm{C}_{\text {surf }} / 6
$$

Thetotal polymer concentration is $2 \mathrm{wt} \%$ for the $\mathrm{P}^{+}$system and 2.5 wt \% for the $\mathrm{HMP}^{+}$system. A value of $\mathrm{a}_{\mathrm{s}}$ of $35 \AA^{2}$ has been used, as justified previously. ${ }^{31}$ N otethat therange of $\phi_{v}$ in Figure 6 is very different for the two polymers. When compared under similar conditions, the storage modulus is considerably higher for $\mathrm{HMP}^{+}$than for $\mathrm{P}^{+}$. Higher $\mathrm{f}_{\mathrm{p}}{ }^{+}$values correspond to lower vesicle volume fractions; this is more evident for $\mathrm{HMP}^{+}$system, since $\mathrm{HMP}^{+}$has lower charge density than $\mathrm{P}^{+}$. Additionally, Figure 7 represents storage modulus as a function of $\mathrm{f}_{\mathrm{p}}{ }^{+}$ for 1 wt $\%$ of $\mathrm{P}^{+}$.

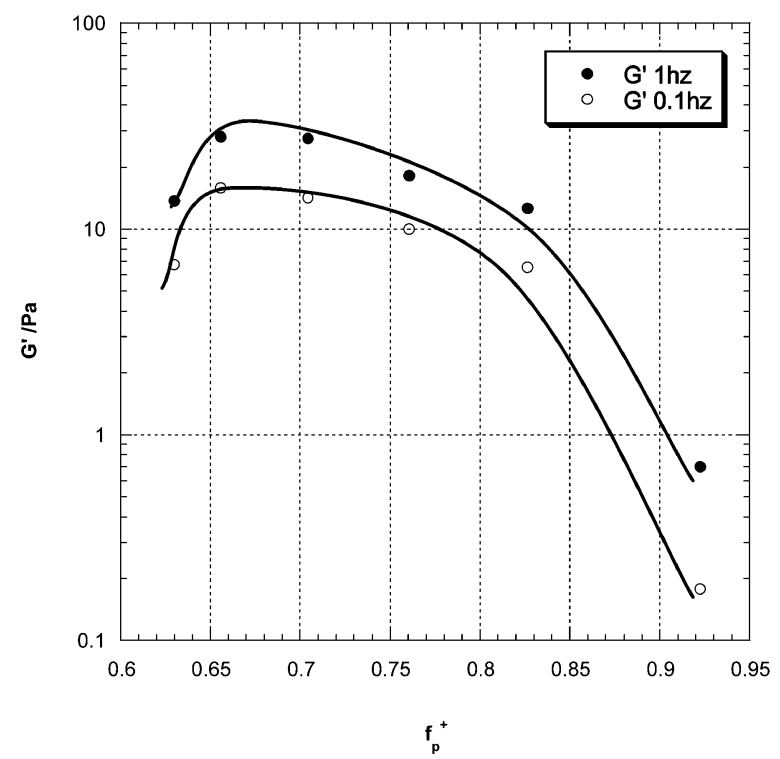

Figure 7. Dependence of storage modulus on the fraction of polymer charge, $\mathrm{f}_{\mathrm{p}}{ }^{+}$, in the $\mathrm{P}^{+}$system. The total polymer concentration is $1 \mathrm{wt} \%$. The lines are meant to be a guide for the eye.

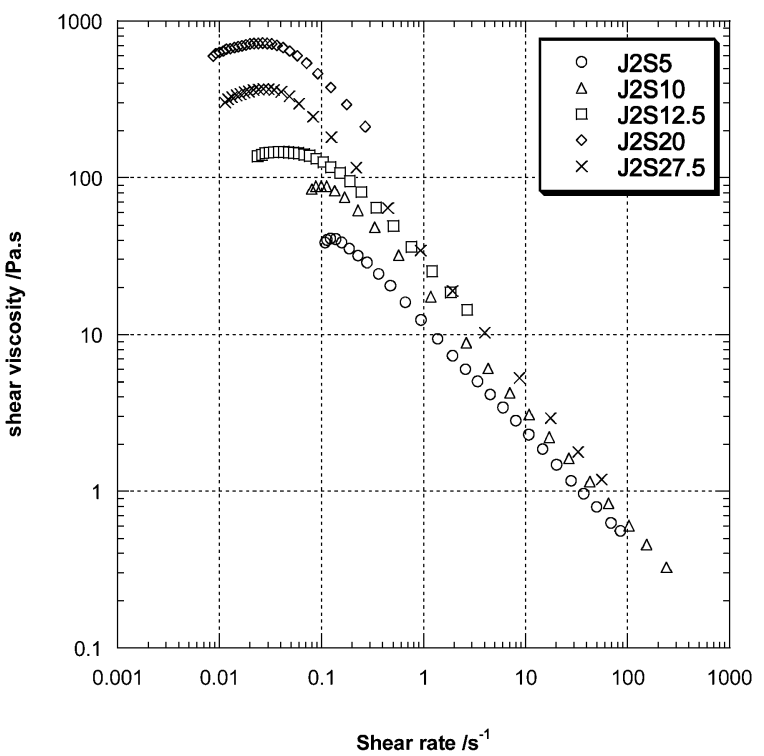

Figure 8. Shear viscosity as a function of shear rate for $2 \mathrm{wt}$ $\%$ of $\mathrm{P}^{+}$at different surfactant concentration. Samples are denoted as J XSy or LxSy where J and $\mathrm{L}$ represent $\mathrm{P}^{+}$and $\mathrm{HMP}^{+}$, respectively, $x$ represents the polymer weight content (wt \%), and y represents the surfactant concentration $(\mathrm{mm})$.

From both figures it can beinferred that first thestorage modulus increases with surfactant concentration. However, at higher surfactant contents it passes via a maximum; after that it decreases, indicating a weaker network.

An analogous behavior is found in the shear rate dependence of viscosity, exemplified in Figure 8. This figure also demonstrates that all the samples are shearthinning with a Newtonian plateau at low shear rates. The progressive addition of surfactant leads to stronger gels, as seen as an increase of Newtonian plateau. The sample J 2S27.5 is an exception since it is close to the neutralization line.

It was al so found that in the $\mathrm{P}^{+}$system, the viscoelastic properties increase monotonically on increasing the total polymer/surfactant concentration, asillustrated in Figure 


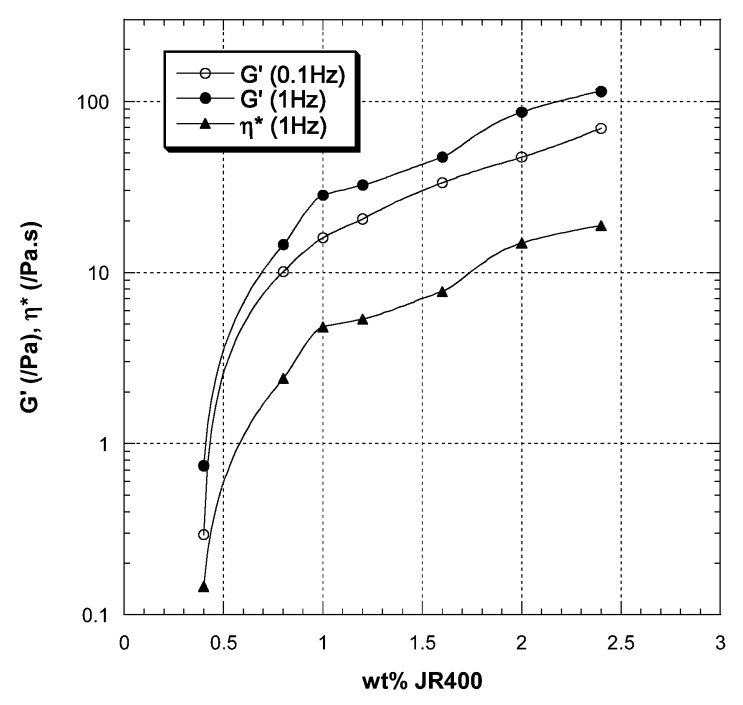

Figure9. Compl ex viscosity and storagemodulus as a function of polymer concentration for the $\mathrm{P}^{+}$system. It can be seen that both properties increase monotonically as the concentration is increased; $\mathrm{f}_{\mathrm{p}}{ }^{+}$is kept constant $\left(\mathrm{f}_{\mathrm{p}}{ }^{+}=0.6557\right)$.

9, for the case of keeping $\mathrm{f}_{\mathrm{p}}{ }^{+}$constant $\left(a t \mathrm{f}_{\mathrm{p}}{ }^{+}=0.6557\right.$, equidistant to the neutral ization line).

cryo-TEM Investigation of Microstructure. To complement the rheological measurements, the microstructural effects connected with the polymer-vesicle association have been investigated by cryogenic transmission electron microscopy. For this technique, during samplevitrification thetemperature is so rapidly lowered that amor phous rather than crystall ine ice is obtained; in this way, self-assembly structures generally remain intact. F or the case of vesicles and other largestructures, artifacts due to rapid freezing should then be quite small. A more serious difficulty consists of obtaining shear-freethin films in the cryo-grid with using highly viscous samples, such as those found for $\mathrm{HMP}^{+}$. Therefore, studies for this polymer had to be limited to a range of polymer concentrations lower than those of the gel-like samples. The polymer effect on the surfactant self-assembly should, nevertheless, bea local effect rather than associated with the long-range formation of a network. Therefore, we believethat themain structural effects of polymer addition can becorrectly assessed and, in particular, the differences between the two polymers used.

Previous cryo-TEM investigations of thesesystems have shown that the polyelectrolytes induce a modification in the vesicle shape and integrity, in particular for the $\mathrm{P}^{+}$ system. ${ }^{28}$ I thecurrent study, a larger number of samples have been extensively monitored by theimaging technique. Figure 10 shows representative micrographs, where typical features are indicated by arrows. The polymerfree vesicle sol ution shows the presence of mainly unilamellar, roughly spherical vesicles (Figure 10a). It can be seen that $\mathrm{HMP}^{+}$associates with the vesicles and creates only small effects on their shape (Figure 10b); dispersed spherical vesicles are shown, where they undergo mi nor changes in their size and shape. ${ }^{28}$ The TEM images give evidence for a strong interaction of $\mathrm{P}^{+}$with the vesicles, since aggregate shapes are strongly altered by an increasing amount of polymer. In $1 \mathrm{wt} \% \mathrm{P}^{+}$and $2 \mathrm{~mm}$ surfactant sample, J 1S2, there is coexistence of faceted vesicles and SUVS (Figure 10c), while in the samples of $2 \mathrm{wt} \% \mathrm{P}^{+}$with $10 \mathrm{~mm}$ surfactant (। 2S10), disklike aggregates coexist with faceted vesicles (F igure $10 \mathrm{~d} 1, \mathrm{~d} 2$ ). At 2 wt $\% \mathrm{P}^{+}$with $20 \mathrm{~mm}$ surfactant (J 2S20), disklike aggregates coexist with faceted vesicles and hol ey vesicles
(F igure 10e1,e2). At 0.4 wt $\% \mathrm{P}^{+}$and $7.5 \mathrm{~mm}$ surfactant ( 0.4S7.5), the mixture is close to phase separation boundary and large irregularly shaped bilayer patches can be observed (Figure 10f).

There is no obvious increase in size of vesicles with either polymer. The polymer-free vesicular solutions contain unilamellar vesicles with diameters in the range 20-70 nm and an average size of $30 \mathrm{~nm}$; with polymer addition the vesicle size distribution observed in the pictures remains apparently unchanged. The cryo-TEM images also indicate the possibility to stabilize vesicle solutions at $2 \mathrm{~mm}$ of surfactant when the polymer $\mathrm{HMP}^{+}$ is present, whereas the polymer-free samples at concentration below $5 \mathrm{~mm}$ are phase-separated (solution + precipitate).

\section{Discussion}

The general and most significant findings in the rheol ogical characterization of themixed polymer - vesicle systems investigated in this work can be summarized as follows: (i) thehydrophobically grafted polycation, $\mathrm{HMP}^{+}$, affects the viscosity and the storage and loss moduli to a larger extent than the hydrophilic polycation, $\mathrm{P}^{+}$; (ii) the number of cross-links is larger with $\mathrm{HMP}^{+}$than with $\mathrm{P}^{+}$; (iii) the cross-links are considerably more long-lived with $\mathrm{P}^{+}$than with $\mathrm{HMP}^{+}$. From thevariations of therheol ogical parameters with composition, we suggest that these findings are quite general, i.e., they do not depend on the particular polymer samples used here, for example, they are not due to the differences in molecular weight. Otherwise, the current systems show several characteristic features of polymer solutions in general and associating polymer solutions in particular, such as shearthinning behavior and viscoelastic properties with dominating viscous effects for long observation times and dominating elastic effects for short times.

The observed rheological properties can be related to two main factors: the polycation-vesicleinteractions and the effects of the polymer on surfactant self-assembly. Let us start by addressing the first factor. The polymervesicle interactions at play are of electrostatic and hydrophobic origin. For $\mathrm{P}^{+}$, only el ectrostaticinteractions account for association, whereas for $\mathrm{HMP}^{+}$thehydrophobic grafts can be directly inserted in the vesicle bilayer. The surface charge density of the vesicles has been estimated to be of the order of 1 charge per $\mathrm{nm}^{2}$ (cf. eq 1 ). The $\mathrm{P}^{+}$ polymer with a high charge density and a mean chargeto-charge contour length of about $2 \mathrm{~nm}$ can efficiently match the vesicle surface charge. For the lower charge density $\mathrm{HMP}^{+}$, where the charge separation is of roughly $10 \mathrm{~nm}$, the situation is less optimal for the interaction with theanionic vesicles. Moreover, $\mathrm{P}^{+}$has a longer overall contour length than $\mathrm{HMP}^{+}$and thus can more effectively wrap around vesicles, with long contact regions al ong the polymer chain, and even connect two or more vesicles. Previous studies show that in systems of strong electrostaticassociation with low content of screening el ectrolyte, the interaction forces can yield gels with very long relaxation times. ${ }^{40}$

For the hydrophobically modified polymer, thecharged stickers can easily anchor in the bilayer, but the smaller number of charges by which the polymer is attached to each vesicleimplies shorter relaxation times. Association of different parts of the polymer molecule with several vesicles may result in theformation of a three-dimensional polymer-vesicle network; the electrostatic interactions

(40) Thuresson, K.; Piculell, L.; Lindman, B. J . Dispersion Sci. Technol. 1999, 20, 663. 


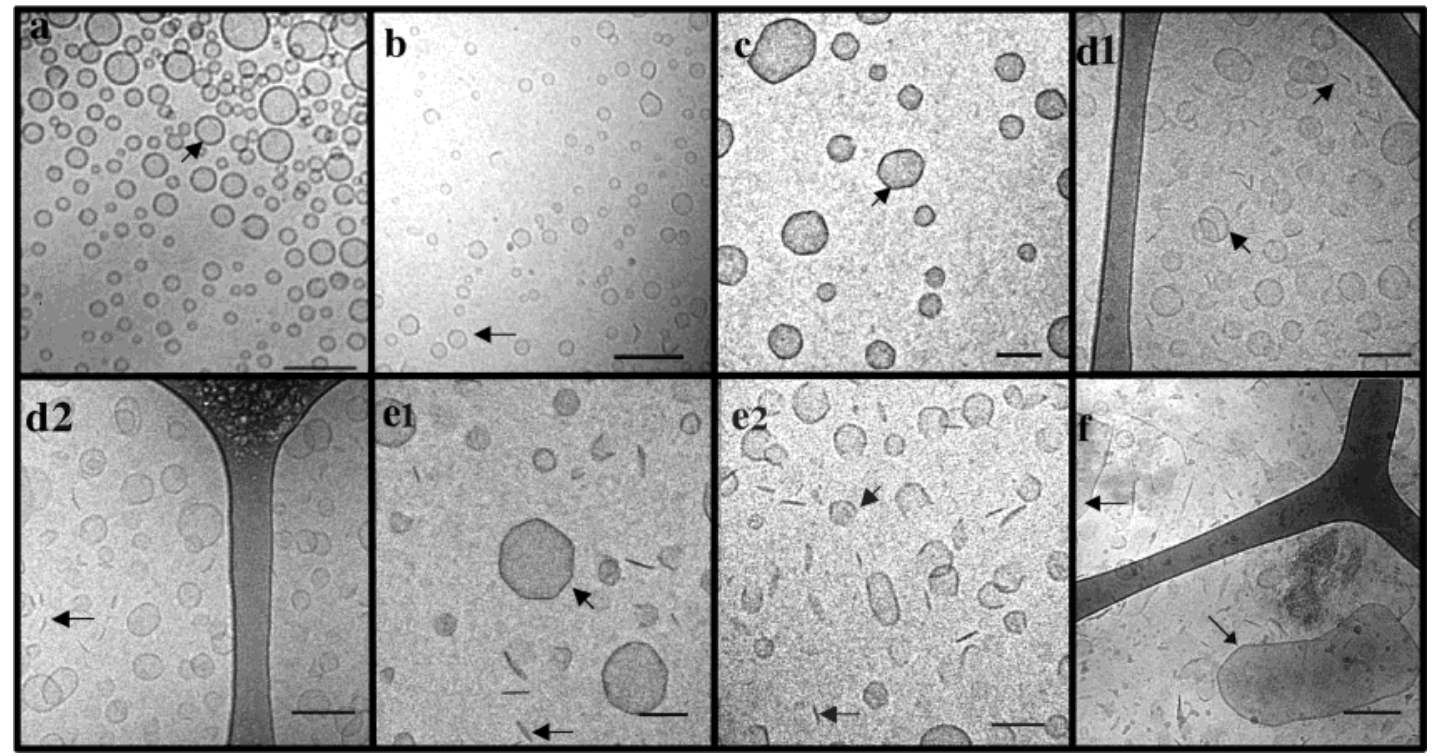

Figure 10. cryo-TEM micrographs of the studied systems at $25^{\circ} \mathrm{C}$. It shows vesicle solutions in different conditions: (a) without adding polymer, where spherical vesicles are dominant; (b) 0.01 wt $\%$ of $\mathrm{HMP}^{+}, \mathrm{C}_{\mathrm{s}}=20 \mathrm{~mm}$, denoting spherical and faceted vesicles (sample L0.01S20); (c) 1 wt \% of $\mathrm{P}^{+}, \mathrm{C}_{\mathrm{s}}=2 \mathrm{~mm}$ (sample J 1S2), the dominant structures are spherical and faceted vesicles; (d1, d2) 2 wt \% $\mathrm{P}^{+}, \mathrm{C}_{\mathrm{s}}=10 \mathrm{~mm}$ (sample J 2S10); (e1, e2) $2 \mathrm{wt} \% \mathrm{P}^{+}, \mathrm{C}_{\mathrm{s}}=20 \mathrm{~mm}$ (sample J 2S20), where the dominant structures are faceted vesicles and disks; (f) 0.4 wt $\%$ of $\mathrm{P}^{+}, \mathrm{C}_{\mathrm{s}}=7.5 \mathrm{~mm}$, where large irregularly shaped bilayer areas are present. Bar $=100$ $\mathrm{nm}$

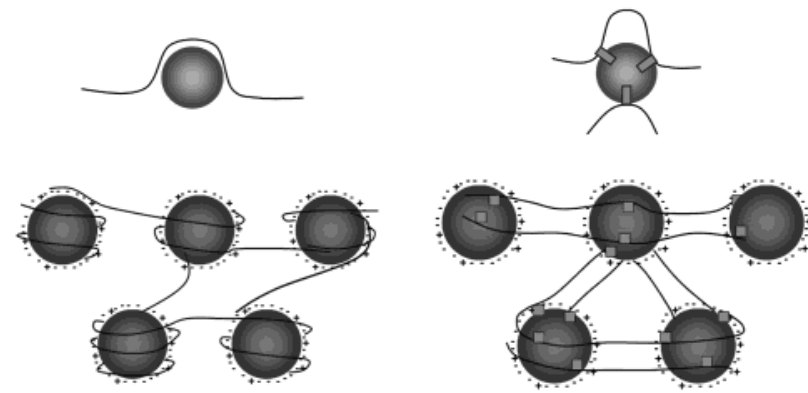

Figure 11. The figure shows a schematic cartoon picture of the suggested association mechanism responsible for the network formation in the $\mathrm{P}^{+} /$vesicle system (left) and in the $\mathrm{HMP}^{+} /$vesiclesystem (right). For simplicity, the polymer chains are represented in a stretched way.

reinforce to some extent the strength of association. An increase of surfactant concentration promotes closer surfactant aggregates and hencethe possibility of cluster formation. This could explain the increase of relaxation time since the cluster network is more protected against deformation. Moreover, the increase of surfactant, and therefore the number of close vesicles, increases the number of bridges between the polyions and thesurfactant aggregates, which causes an increase of the storage modulus, G'. Figure 11 summarizes in a schematic way theassociation model proposed here, assuming nochanges in aggregate structure and emphasizing the differences between the two polymer systems discussed so far.

Besides the polymer-vesicleinteractions, modifications on vesicle structure, fluidity, and integrity due to the association could also underpin the rheol ogical behavior. The cryo-TEM imaging unequivocally shows that the vesicle structure undergoes considerable changes upon polymer addition. Such changes are relevant in systems where equilibrium vesicles are present and a net charge is essential for thermodynamic stability. An oppositely charged polymer will affect not only the vesicle-vesicle interaction but also the local vesicle charge and the molecular packing in the surfactant bilayer. For both polymer systems, vesicles with regions of zero or al most zero curvature and an irregular polygonal shape, here termed as faceted vesicles, are clearly observed by cryoTEM. Their occurrenceis comparatively more pronounced for the case of $\mathrm{P}^{+}$than for $\mathrm{HMP}^{+}$. F or the latter, a more prominent feature in the imaged viscous solutions is the presence of clusters of vesicles where both the globular and, to a less extent, the faceted shape are seen. F or $\mathrm{P}^{+}$, the most characteristic feature is the existence of a large number of holey vesicles, faceted vesicles, and disklike aggregates, indicating a more significant departure from the integral globular vesicle shape.

A high charge density polymer is expected to affect an oppositely charged vesicle in two main ways. First, the polymer charge will affect the curvature of the surfactant films. A surfactant film with a positive curvature due to a net charge will have its curvature reduced on charge neutralization. Second, the conformational state of the surfactant alkyl chains can also be changed. For ionic surfactants, it is known that theKrafft point, or thechain melting temperature in the case of bilayer-forming amphiphiles, are strongly affected by electrostatic effects, e.g., addition of electrolyte or increase in counterion valency. Thescreening of the headgroup repulsions by an el ectrolytestabilizes both the crystalline and themicellar/ bilayer state, but the effect is more pronounced for the more organized state where the area per molecule is smaller. Hence, the addition of electrolyte typically increases the Krafft point or the chain melting temperature. ${ }^{41,42} \mathrm{~A}$ polyion, which can be seen as a giant counterion, is similarly expected to increase the melting temperature and thus induce surfactant crystallization in the vesicles in a certain temperature range.

A freezing of the alkyl chains, with loss of liquidlike motional freedom, affects surfactant aggregation profoundly. The formed network probably inhibits crystal packing and sedimentation, keeping the solidlike surfac-

(41) Marques, E. F, Khan, A.; Lindman, B, Thermochim. Acta 2002 394, 31-37.

(42) Blume, A.; Garidel, P. Lipid model membranes and biomembranes, Handbook of Thermal Analysis and Calorimetry; Elsevier: Amsterdam, 1999. 
tant in solution. If upon freezing the vesicles remain kinetically trapped, theremay bechanges in thesurfactant films to a less fluid state, a consequence of which may be the formation of planar regions in the vesicles - hencethe observed faceted vesicles. An alternativemechanism could be an in-plane surfactant segregation induced by the polymer "adsorption" onto the bilayer, owing to the preferential interaction of the polycation with theanionic surfactant SDS. The consequent heterogeneous surfactant packing in the bilayer plane could also induce morphological changes. Segregati on effects have been previously seen for mixed ionic-nonionic lipid vesicles upon interacti on with an oppositel y charged pol ymer. ${ }^{43} \mathrm{H}$ owever, such effects are probably less likely in our system since surfactant-surfactant interactions herearestronger than for an ionic-nonionic surfactant film.

Formation of hollow icosahedra in catanionicsurfactant mixtures has been detected for crystallized chains in previous studies, where it was also found that the aggregates werestabilized by the presence of pores located at the vertexes of the icosahedra. ${ }^{44}$ Such states would be unstableat high polymer concentration, and vesicles would be easily disrupted. A first consequence could then bethe formation of holes in the vesicles; a second more dramatic consequence could be the fragmentation of vesicles into moreor less planar bilayer fragments or disks. Disks seem to be the preferred arrangement of the surfactant aggregates when the polymer positivecharge concentration is high enough.

The insertion of the charged grafts, in the case of the $\mathrm{HMP}^{+}$seems to be less disruptive of the original vesicle shape. I n studied charged vesi clesystems wherelow molar fractions of an oppositely charged surfactant have been added, only a small increase in the chain melting temperature is observed and the vesicle structure remains intact. ${ }^{45}$ One could expect by comparison that a polymer with a relative small number of charged hydrophobic chains inserted in the surfactant films will have a relatively minor effect on vesicle shape and fluidity.

These changes in the state of the surfactant aggregates can be expected to influencethe formation and properties of the polymer-surfactant network. For instance, a liquid-solid transition for the surfactant film in the network would havetheeffect of consi derably lengthening the lifetimes of cross-links. The high relaxation times deduced for the $\mathrm{P}^{+}$system could then be explained, not only by optimal polymer - vesicle interactions but also by the crystallization of the surfactant in the vesicles. The detachment of a polyion from a crystallized vesiclesurface would have a high free energy of activation. Regarding the formation of disklike structures, one can speculate that an additional crowding effect, perhaps similar to the card-house effect found for clays, ${ }^{46}$ could well contribute to an enhanced network formation and strength. $\mathrm{HMP}^{+}$ has a lower charge density, and the effects on the surfactant packing are weaker than with $\mathrm{P}^{+}$. Disks are detected to a negligible extent for the $\mathrm{HMP}^{+}$system, and considerably fewer vesi cles acquire a pronounced faceted shape compared to those in $\mathrm{P}^{+}$mixtures. Figure 12 illustrates schematically the relation between the aggregates formed in the two polymer systems and the polymer concentration.

Onefinal point to bediscussed is the viscosity maximum as a function of composition, observed for the $\mathrm{MMP}^{+}$system

(43) Cromwell, K. V.; Macdonald, P. M. J . Phys. Chem. 1998, 102, 9091.

(44) Dubois, M.; Zemb, T.; et al. Nature 2001, 411, 672.

(45) Brito, R. O.; Marques, E. F. Manuscript in preparation.

(46) Kroon, M.; Vos, W.; Wegdam Phys. Rev. E 1998, 57, 2.
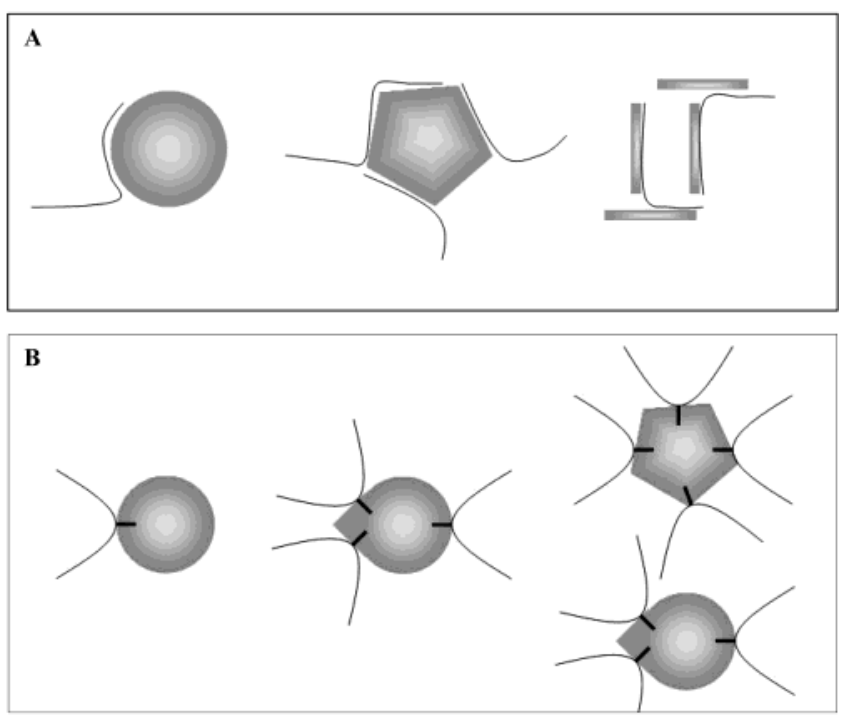

Figure 12. A schematic representation of the surfactant aggregate shape in the presence of $(A) \mathrm{P}^{+}$and $(B) \mathrm{HMP}^{+}$, from relative low polymer concentrations (left pictures) to relative high polymer concentrations (right pictures).

(Figures 6-8). For mixed systems of a HMP and a micelleforming surfactant, the rheological properties show a markedly nonmonotonic behavior with a maximum as a function of composition; as mentioned abovethis is related to the stoi chiometry, i.e., the rati o between hydrophobic groups on the polymer molecules and the number of micelles. In the vesicle case, the aggregation number is orders of magnitude higher than in the case of micelles and a simple estimate shows that the same mechanism cannot apply. I nstead weseethat the decrease in viscosity occursas thetwo-phaseregion indicatingassociativephase separation is approached. Previous mi croscopy observations show the presence of large irregularly shaped "membrane-like" fragments at $\mathrm{f}_{\mathrm{p}}{ }^{+}=0.55$, suggesting that these are precrystallites. ${ }^{28}$ Therefore, we interpret the decrease as a result of onset of microscopic phase separation and association that reduces the extension of the polymer chains.

It should be pointed out that the picture of the possible mechanisms underlying the rheology and network formation of the polymer-vesicles systems described here remains largel y speculativeat this stage. I nferences were made essentially from the comparison of polymer structures and from the inspection of microscopy data. Clearly, a more in-depth picture requires the collection of more experimental data for these systems (or even variation of the cosolute chemistry). In this respect, we are currently carrying out calorimetric and rheological measurements as a function of temperature and composition, to be presented in a forthcoming report.

\section{Conclusions}

A highly viscous gel-like mixture is obtained by mixing anionic vesides with two different cationicpol yel ectrolytes. Variationsin polyelectrolyteand surfactant concentration strongly influence gel properties. For the more highly charged polymer, an elastic gel is found and relaxation times are long, explained by both the charge density and a proposed surfactant crystal lization in thevesicles. With the shorter and less charged hydrophobically modified polyelectrolyte, the number of cross-links is higher, while the mixtures have shorter relaxation times. cryo-TEM shows that thevesiclestructureis affected by thepolyions in different ways. Polygon-shaped vesicles and disklike 
fragments appear due to the presence of the hydrophilic polyelectrolyte since the polycation is likely to induce a crystallization of the vesicle surfactant film and thus reduce its flexibility. The higher charged pol yelectrolyte induces more marked changes in the vesicle structure than the lower charged polymer.

Acknowledgment. F.E.A. acknowledges Fundação para Ciência e Tecnol ogia (FCT) for a research grant (ref. SFRH/BD/8168/2002). The Colloid Group in Coimbra
University is supported by grants from the $F$ undação para Ciência eTecnol ogia (FCT) (ref. POCTI/QUI/35415/99 and POCTI/QUI/45344/02). We acknowledge Swedish Research Council for financial support. E.F.M. acknowledges Centro de I nvestigação em Química (U.P.)-linha 5 (FCT) Portugal for financial support. We are grateful to the Biomicroscopy Unit at the Chemical Center, Lund University and to J ohanna Borné for useful assistance.

LA049783I 